\title{
An Integrated Computer-Aided System and Parts Component Repository for Shaft Design Automation
}

\author{
Ki-Yin Chang \\ Associate Professor, Department of Merchant Marine, National Taiwan Ocean University, Keelung, Taiwan. \\ Gene Eu Jan \\ Associate Professor, Department of Computer Science, National Taiwan Ocean University, Keelung, Taiwan. \\ Kevin C. M. Fan \\ Graduate Student, Department of Computer Science, National Taiwan Ocean University, Keelung, Taiwan.
}

Follow this and additional works at: https://jmstt.ntou.edu.tw/journal

Part of the Engineering Commons

\section{Recommended Citation}

Chang, Ki-Yin; Jan, Gene Eu; and Fan, Kevin C. M. (2002) "An Integrated Computer-Aided System and Parts Component Repository for Shaft Design Automation," Journal of Marine Science and Technology. Vol. 10: Iss. 1, Article 10.

DOI: $10.51400 / 2709-6998.2303$

Available at: https://jmstt.ntou.edu.tw/journal/vol10/iss1/10

This Research Article is brought to you for free and open access by Journal of Marine Science and Technology. It has been accepted for inclusion in Journal of Marine Science and Technology by an authorized editor of Journal of Marine Science and Technology. 


\section{AN INTEGRATED COMPUTER-AIDED SYSTEM AND PARTS COMPONENT REPOSITORY FOR SHAFT DESIGN AUTOMATION}

\begin{abstract}
Key words: Shared component database, computer-aided integration, parametric design, shaft design, object-oriented database (OODB), common object request broker architecture (CORBA)
\end{abstract}

Ki-Yin Chang*, Gene Eu Jan** and Kevin C. M. Fan***

\section{ABSTRACT}

This research proposes an Object-Oriented Database (OODB) system that integrates computer-aided systems and parts component repository to automate a traditional propulsion shaft design for a shipyard. The software system is based on three concepts: an objectoriented graphic user interface, a parametric design, and a shared component database. Calculations of strength, alignment, vibrations, and sag \& gap for the shaft design can therefore be completely integrated. All of the data produced in the CAD processes can be managed, integrated and applied in the OODB system. Furthermore, to easily integrate the systems developed at different periods of time, a Common Object Request Broker Architecture (CORBA) infrastructure is introduced to facilitates an object-oriented data flow bus exchanging data during the design stage. In the estimation or design process, all of the design and drawing output can be completed in a considerable short time. By integration of the shaft design process, precise estimation of design cost can be determined. A highly efficient production can be made due to the fact that working hours, costs and construction span times are reduced.

\section{INTRODUCTION}

Marine shipbuilding and engineering design is an achievement combined with various theories, procedures, experiments and arts. A marine ship design was an arduous task, and it often took a vast amount of scientific data and calculations without the aid of computer in the past. The data transfer itself was laborious and indispensable work. All the regulations and requirements concerning ship design process should be properly implemented. A shaft design system for ma-

Paper Received Sep. 6, 2001. Author for Correspondence: Ki-Yin Chang. *Associate Professor, Department of Merchant Marine, National Taiwan Ocean University, Keelung, Taiwan.

**Associate Professor, Department of Computer Science, National Taiwan Ocean University, Keelung, Taiwan.

*** Graduate Student, Department of Computer Science, National Taiwan Ocean University, Keelung, Taiwan. rine propulsion is based on certain analytical theories such as material strength, vibration analysis and bending deformation, etc. Because various design theories are involved, it is difficult to take into account all of the possible factors. Nevertheless, a shaft design system is one of the most important designs in shipbuilding engineering, and no omissions or carelessness can be tolerated.

Nowadays, in Taiwan, computers still have not yet been extensively used in complex calculations, data transformation, database utilization, and standardized computer-aided drawing. The design by a finite element method usually requires lots of times for preparation and calculation due to a large amount of engineering data manipulated. A computer can be of great assistance in repeated calculation, however the integrated design still heavily relies on traditional manmade work. Therefore, computer-aided systems do not play a full role in the shaft design process. On some critical occasions such as tender offer estimates, it is difficult to obtain an accurate cost analysis because of insufficient information. Shipbuilding designer would be obliged to rely on their experience to evaluate and reduce the cost estimate in order to obtain a tender offer. Errors and omissions were often found during construction that caused irremediable cost losses. Thus, an extensive use of computer especially in data retention, calculation and transmission is made to facilitate shaft system design that allows repeated works of calculation, analysis and drawing. Furthermore, even with limited data, this system is still capable of estimating the costs for the tender's requirements.

In the early years, a computer-aided system was mainly used for analysis, drafting, and manufacturing. It had to be combined with manual tasks to complete the design and manufacturing. In a highly competitive manufacturing industry, the total cost of design and manufacturing can be reduced and hence increase the competitiveness of the products if computers can integrate the whole working procedures. Computer-aided integration has therefore become an inevitable trend. Many industries have achieved a great deal of success 
between non-integrated and integrated systems [1]. It has been proven that integration of design and manufacturing is an effective strategy in reducing costs and improving quality [2]. In CAM (Computer-aided Manufacturing or Computer-aided Management) for the shipbuilding industry, there are some enhanced and integrated of state-of-the-art systems for ship design and production [3-5]. A concise and explicit integrated system is an essential tool in improving these techniques. There is an instant demand for introducing the OODB database system for shaft analysis, design and drawing system integration. An explicit shared database will assist data transfer in the development of future projects.

The Object-oriented Database (OODB) proposed by the Object Database Management Group (ODMG) introduces objects to the realm of database systems by extending object-oriented programming languages with database capabilities [6]. Instead of a Relational Data Model (RDM), the Object Data Model (ODM) adopted by OODB not only describes the objects in the real world more precisely but also supports object-oriented semantics such as encapsulation, polymorphism and inheritance. In this paper, an ODM-based data model is provided to describe the parts in the CAD system and then to store these parts description into the OODB.

The Common Object Request Broker Architecture (CORBA) [7], a standard proposed by the Object Management Group (OMG), revolutionizes the distributed processing environment by specifying an object-based infrastructure-Object Request Broker (ORB). This infrastructure provides interoperability between applications written in various languages and running on multiplatforms. Multiple object systems are thus seamlessly interconnected in heterogeneous environments. The shaft design process is complicated and may involve many design stages. Each design stage is characterized by its own platform, language and design demands, integrated multiple design stages are often involved in these heterogeneous environments. To make dissimilar CAD design systems exchange data easier, the CORBA infrastructure is therefore used.

For distributed environment characteristics such as a shared database, shared business logic or message handling system and the individual front-ends, the legacy system models have progressed into a new paradigm. The characteristics in CORBA and OODB should be integrated to satisfy the requirements of the current distributed applications. Of the many CORBA/OODB integration models, the most renowned one is the Object Database Adaptor (ODA) suggested by ODMG [8]. Another illustrious one proposed by Sheu et al. is the integration model, which integrates the Object Transaction Service (OTS), Concurrency Control Service (CCS) and OODB [9]. When a 3-tier architecture of
Sheu's model was adopted, it does not require having the knowledge of OODB for the designers of the CORBA side. The system model is automatically translated to the OODB side through ORB and Recoverable Object (RO). Therefore, Sheu's approach is adopted in our CORBA/OODB integration model.

The aim of this study is to propose a CORBA/ OODB tool by which a computer-aided shaft system can be constructed with a parts repository system. The OODB shaft design system, which is based on the structure presented by Chang [10], is characterized by using a parametric design concept to reach an automatic drawing process with shared data and improved user interface. An object-oriented component database simplifies data input and output, and widely utilizes a shared database to reduce data collection and data input. Furthermore, the component design automation is implemented by a system which is established with an objectoriented component database. Communication between users can be achieved easily using an object-oriented graphic user interface.

In the next section, the traditional shaft design processes and its related computer-aided systems are first introduced. A detailed system analysis is described in section 2. The system architecture of parts component repository will be presented in section 3 . The integration processes for the new system presented in this paper and the traditional ones will be illustrated in section 4 . The subsequent section will provide an example to demonstrate the integrated system. Finally, a conclusion is given in section 6 .

\section{TRADITIONAL PROPULSION SHAFT DESIGN PROCEDURE}

The function of a shaft is to transfer the power from a main engine to a propeller that rotates and carries the ship forward. Thus, a shaft design is an essential part to ship design and construction. In general, a marine propulsion shaft system consists of a tail shaft, several immediate shafts, a thrust shaft and several crankshafts. Each part of the shaft is connected with a flange coupling.

On the whole, a shaft design includes four parts: strength calculation, vibration calculations, alignment calculation, and sag \& gap calculation. With these four steps of calculation, the shaft drawing is then determined. The detail of shaft design is described as follows:

\section{Strength Calculation}

In order to prevent a rotating shaft from cracking or breaking, the shaft must have enough strength. That is, the tensile stress of the shaft must be under the 
allowable working stress. Usually the strength of the shaft is calculated according to one or more rules or registers such as the $\mathrm{ABS}, \mathrm{CR}, \mathrm{NK}$, and $\mathrm{LR}$, etc. The shaft design system in this research is based on the ABS and CR safest rules [11] to meet the design standard. The diameter and length of the shaft are thereby determined.

\section{Vibration Calculations}

Shaft vibration includes torsional vibration, axial vibration and whirling vibration. The shaft generates moment and torsion due to its weight and rotation. When the rotation speed is the same as the torsional cycle, the amplitude of the vibration will increase due to resonance and additional force generated. When the shaft stress exceeds the limit of the allowable stress for continuous operation, this speed is the so-called critical speed of the shaft. In order to maintain stability and to avoid too much noise and vibration, the shaft speed has to be kept away from the critical speed $\pm 20 \%$. The purpose of the torsional vibration analysis is to compute the critical speed of the shaft. The maximum additional force generated from torsional vibration will therefore not exceed the allowable working stress.

In the same manner, the purpose of the axial vibration calculation is to obtain additional force generated from the main engine under a working condition, and the whirling vibration calculation is used as a reference to reduce friction in the shaft bearing.

\section{Alignment Calculation}

The main purpose of the alignment calculation is used to adjust a horizontal span and vertical offset of all the bearings to a suitable loading position [12]. The number of bearings and the bearing position may be arbitrarily chosen. A suitable loading position can prevent the bearing load from exceeding the rated load and keep the bearing load well distributed.

Generally speaking, a shaftline in the athwart direction is not a straight line since propeller, main engine, and flange loads are not uniformly distributed, and asymmetrical stress and bending moment are then generated. Using vertical offset and horizontal bearing position adjustments, the bearing load can be adjusted to a satisfactory distribution.

\section{Sag and Gap Calculation}

The designed horizontal position and vertical offset of the shaft bearings are determined after the alignment calculation is completed. Because the bearing offset is too small to be easily measured and adjusted during installation, the sag \& gap method is introduced to solve and establish the alignment. The sag and gap calculation precalculates the sag and gap of the shaft coupling when the flange couplings are not yet connected. The gap is the angle difference between the bottom and top for the vertical gap, whereas the sag is the distance between the coupling flange centers in the vertical and horizontal directions. With the results of the sag \& gap calculation, the vertical offset of designed bearings can be installed correctly. In short, once the strength calculations are completed, shaft arrangement in primary design can be used to determine the number of bearings and the size of each bearing. At the same time, all of the vibration, including the torsional vibration, axial vibration and whirling vibration, are used to avoid the critical speed and to limit the additional stress and friction when the shaft is operated under normal conditions. The alignment calculation determines the horizontal position and vertical offset of shaft bearings. All of the bearings should then operate under the allowable working stress. To ensure that the shaft is installed as designed, the sag and gap calculation precalculates sag and gap of the shaft coupling before the flange couplings are connected. The basic shaft design procedure is thereby completed. If one of these procedures is not carried out as required, all of the design work must be repeated until all of the requirements are satisfied.

\section{SYSTEM ARCHITECTURE}

The architecture of this shaft design system includes three major subsystems: Data Exchange Infrastructure subsystem, Data Storage subsystem, and Shaft Design Interface subsystem as shown in Figure 1.

\section{Data Exchange Infrastructure Subsystem}

This paper proposes a Data Exchange Infrastruc-

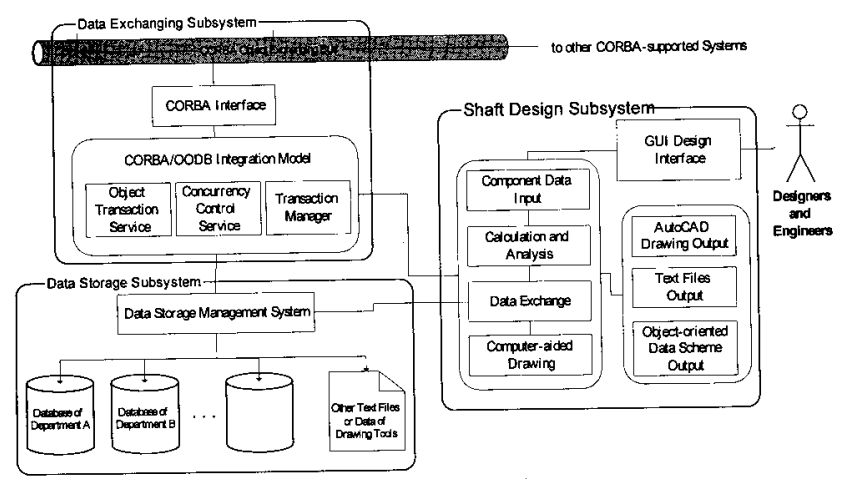

Fig. 1. System architecture. 
ture subsystem that adopts the CORBA technique to interconnect the object-oriented parts data between dissimilar design systems. The Data Exchange Infrastructure subsystem provides a common object data exchanging bus across various programming languages, diverse operating systems and different run-time environments. Through the Data Exchange Infrastructure subsystem, data exchanges of design system at different time periods developed software are made possible and parts component exchanges in different divisions are made convenient. In most cases, once legacy design systems are connected with the Data Exchange Infrastructure subsystem by implementing CORBA adapter for particular programming language, the system can exchange data with other design systems and rarely rewrites its own programs. At present, CORBA serves as an adapter for various programming languages to interconnect systems developed by previous designers. In this paper, strategies adopted for integrating different systems are divided into two phases: 1. It is analyzed that the parts data used for legacy systems can then be transformed into the objectoriented formats as the properties of the objects. The procedures in the original program, which process the parts data, can also be transformed into the objectoriented formats as the behaviors of the objects. Meanwhile, the object encapsulation is considered as a medium for transforming phases.

2. Having been stored into the OODB, those objects transformed can be automatically turned from the OODB-based objects into the CORBA-based ones by using the RO object technique proposed by Sheu et al. [9].

\section{Data Storage Subsystem}

The object-oriented techniques offer three semantics: inheritance, encapsulation and polymorphism. The components are more precisely simulated than by traditional methods. The encapsulation prevents component characteristics and data exchange methods from tedious data translation processes that are unavoidable in traditional methods. These techniques have been extensively used in many other fields, especially in CAD/CAM design systems.

The OODB system stores object descriptions in the database with object-oriented techniques. Comparing with RDBMS, the OODB system has an advantage that the data stored in the database contained not only data properties but also encapsulation of data process. The various design departments are usually involved in a shaft design project which is a time-consuming and laborious task. All of the data are deposited by means of specific value when a traditional RDBMS is em- ployed as a platform for data exchange. It is impossible to obtain the entire information of parts by a parts data exchange due to the fact that relative procedures and logical judgment of data process are often encoded in designed program by each department. In practice, the data exchange often demands specific formulas developed by designers or specialists to make technical explanation of data, procedures, and logic judgment of each and every parts information; furthermore, its complexity of handling time is $O\left(N^{2}\right)$, where $N$ is the total number of parts. The implementation of the object encapsulation by means of OO techniques, enables the realization of automation of parts information exchange with its complexity of handling time being reduced to $O(N)$. Mechanical or shaft designs demand a great deal of try and error test for their parts, thus the object encapsulation has its practical importance. Therefore, this shaft design system can make use of OODB as a component database, and data exchanges are made easier because tedious translation processes are no longer necessary.

\section{Shaft Design Interface Subsystem}

The shaft design system architecture consists of four parts; component data input for creating parts data, calculation and analysis for database design generation, a storage subsystem for component-oriented data sharing and exchanges, and computer-aided drawing for drawings and data output.

\section{Component data input}

This system adopts an objected-oriented graphic user interface (OOGUI) to make data input easier and more accurate. The OOGUI is also combined with database management (DBMS) characteristics, such as validation, integration and data sharing to make sure that the component database is correct and updated and has a higher re-use rate.

\section{Calculation and analysis}

The calculation and analysis methods in this system were based on mechanical design theories. Not only does it calculate and analyze data, it also modifies data simultaneously. For enhancing design efficiency, it exchanges data between the output data and database system, and it can also make the output database synchronous.

\section{Data exchange}

The major bottleneck in CAD/CAM integration is the data exchange [13]. Instead of the traditional Relational Database Management System (RDBMS), the OODB technique is adopted to manage a large number of complex data types in the CAD/CAM design system. The dataflow in this storage subsystem is designed with a dynamic data exchange (DDE) technology. It can 
store all of the data into the database directly and exchange data with the design system without delay. If the subsystems are connected to the main system, data flow can pass from the database through the administration interface of the main system to any authorized subsystem. All useful data can be shared with subsystems and maintain identical data-files. Therefore, this system can connect various subsystems, share data, and select multiple inputs.

\section{Computer-aided drawing}

The function of computer-aided drawing which can generate a drawing chart for the production line is to use output data from the design system to produce designed drawings. A computer-aided drawing system can link to the database, retrieve data from the database and draw the result using a parametric design. In so doing, errors are avoided and system flexibility is thus increased.

Figure 2 shows the relationship between these four subsystems. When data is calculated for the first time, the data comes from an input device. The system will check the data using validation and integration and then record the data into the storage subsystem. The same data can be used repeatedly until validation is incorrect or the data are updated. While recalculating the data, the main system will retrieve updated data from the database and share them with other subsystems. After analysis, the main system will update the database with the newest output from the other subsystems. The system output data shows not only the output with text but also with the computer-aided drawing. With this architecture, the shaft design work can be integrated and the routine design is made possible.

\section{INTEGRATED COMPUTER-AIDED DESIGN OF SHAFT}

This integrated shaft design system has three main properties; the object-oriented graphics user interface, parametric design, and distributed component-oriented database processing and linking.

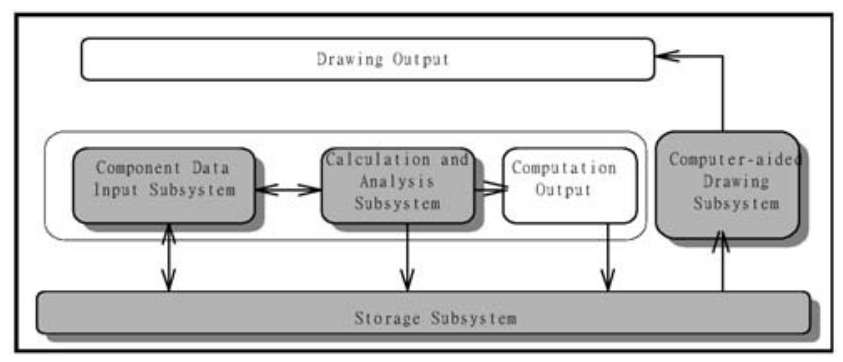

Fig. 2. The architecture of the shaft design system.

\section{Object-oriented Graphics User Interface}

The design effort will be reduced by object-oriented graphic user interface in the CAD system. Most computer-aided systems enhance their user interface and become more and more friendly. The characteristics of graphic user interface are convenient data input and modification, understandable data, and simple data retrieval. Compared to modern computer-aided design systems, traditional design systems simply involved inputting data into files, executing programs and outputting the results. In order to input data correctly, users had to be proficient in traditional design systems. During calculation and analysis, they could not predict what errors would occur. In contrast, with the objectoriented graphics, each object has its own special meaning by using graphic representations and initial value displaying.

\section{Parametric Design}

In traditional drawing methods, the entire drawing had to be redrawn or modified when any portion of the design had a little change. The design process required much more time for modification, particularly for complicated drawings. When the parametric method is implemented, we can speed up the redrawing process with efficiency. The parametric design concept involves representing every part of the shaft with a specific parameter. Because the shaft arrangement drawing has been drawn repeatedly to check for errors during the shaft design, a parameter for each part can be represented by a distinct design parameter. As long as any parameter is changed, a new drawing can be created routinely using the computer-aided drawing system [14]. When drawing with the parametric method, users merely input the designed parameters and then a new drawing will be generated. That is the main advantage of parametric design. Most of output parameters are the same for changing any element size in design. The parameters are shaft length, shaft diameter, bearing location, resistance point location, etc. In traditional methods, all of the drawing elements must be redrawn when the designed parameters has been changed; there would be a time-consuming process and errors could inevitably occur. Although the computer-aided drawing system is very convenient, the parametric design can save much more time [15].

\section{Distributed Component-oriented Database Processing and Linking}

For any design, the foundation of analysis is to collect relative information. A computer-aided design 
is based on the database construction. The database will not only provide and store the designed data, but also maintain data validation systematically. In addition, a database can provide data to other systems and serve as a linking channel for data sharing. In some computeraided systems, the parts database and data records must be shared with other design systems for different department designers. However, the contents in the database are presented using a series of numbers; therefore, without original database designers, these numbers cannot be understood and used by other people. Therefore, the only function of those databases served as storage for data. The data storage subsystem of this shaft design system not only stores parts data with their attributes, but also uses the object-oriented technique concept to encapsulate the behavior of the parts components. By constructing data with the object-oriented technique and storing it into the OODB, the designers do not need to memorize the physical data arrangement method. The designers can also make sure that the transaction semantics and the data integrity are maintained during the design, especially for teamwork on a huge design project.

The CORBA technique is used to provide open standards for data exchanges across various design systems and different design departments. With the CORBA framework, a new design system can be integrated with old systems without any difficulty. The old systems can be connected to the entire design system with the open standardized interfaces specified by CORBA. Through the CORBA infrastructure, any given old design system can be executed on multiple platforms or developed using various programming languages, and exchanges data with other systems, as shown in Figure 3. Therefore, the proposed data sharing subsystem can make the dataflow more speedy and easy.

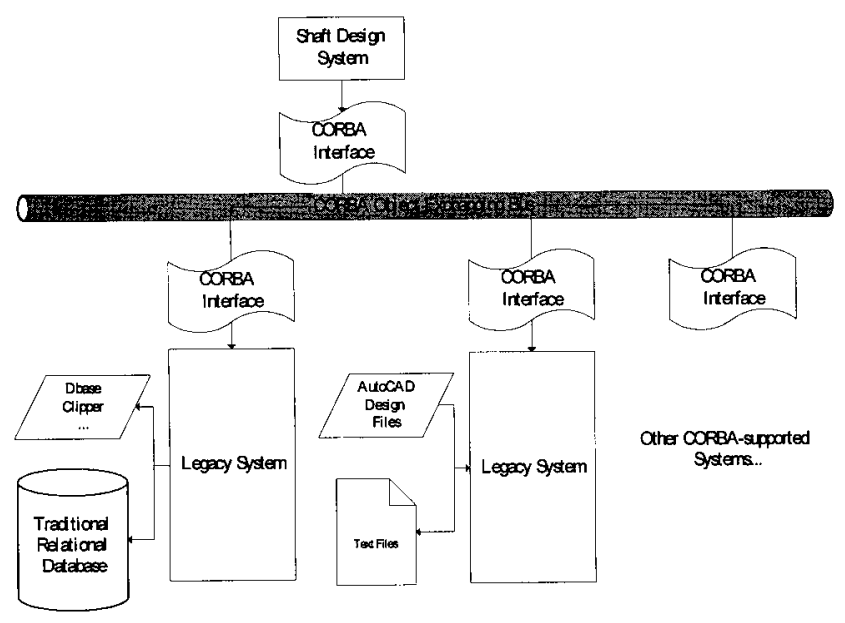

Fig. 3. Data sharing subsystem.

\section{IMPLEMENTATION}

Based on the shaft design system presented by Chang (1996), the current system improves the object data description, data exchange architecture and user interface. This design system uses a high level language, Fortran, to carry out the strength calculation, shaft alignment, vibration calculations and sag \& gap calculation. It utilizes an object-oriented graphic user interface to make the design procedures more uncomplicated and understandable. The construction of a commonly distributed object-oriented database can exchange data in the dynamic data exchange mode. The main system connects the drafting system mechanically, reads the data, and draws the output data. In addition, it can link with other support systems. The data inputs and outputs can be routinely performed to reduce the time for collecting data as well as the possibility of making mistakes. Figure 4 illustrates data input component of this shaft design system.

The object-oriented user interface in this system uses buttons to execute each object procedure. It shows executable calculations using a real line and impossible calculations with a gray line. This interface can assist users in operating the system and input data with convenience and ease. This system can directly store data into a shared database and then connect other subsystems through the database. It also exchanges data between subsystems dynamically to simplify I/O (input and output) work. A parts component repository database is attached to this system as shown in Figure 5. It can choose parts systematically, update the parts database and insert new parts into the database. With the database management system (DBMS), the system re-usability is increased and incorrect modification procedures are avoided. This system will show the first draft

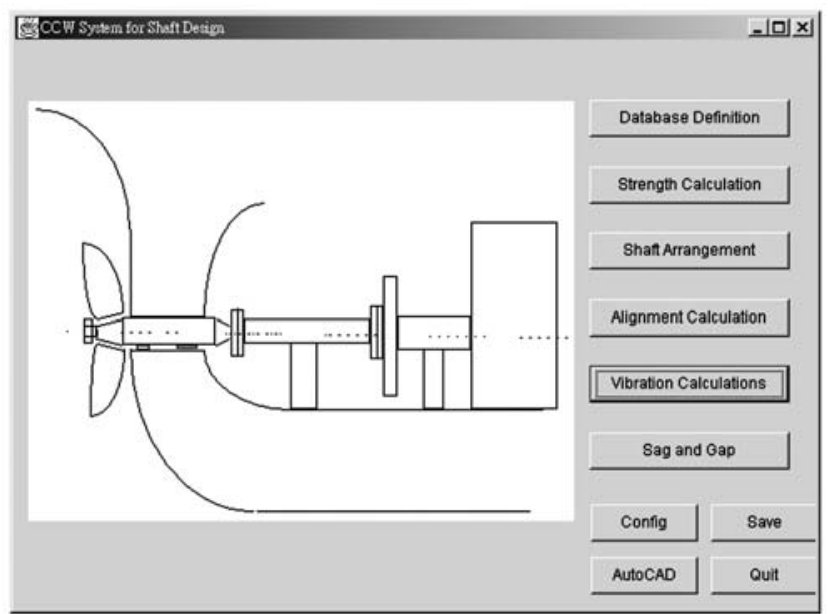

Fig. 4. Main system. 
to the designers and thus facilitate error checking and amendment. After the calculation process is completed, the system will update the data into the OODB database as shown in Figure 6.

The output files of this system are distributed into four parts: text file (*.txt), draft drawing file, database file, and AutoCAD file. The output text data with the ASCII code can be edited with other editor tools. The draft drawing output data can be drawn using other drawing systems as shown in Figure 7.

The most important part of this design is the AutoCAD drawing output. Based on a database supported by other auxiliary systems such as sag \& gap AutoLisp program, the AutoCAD drawing file will connect the main system and a drawing system. This program uses the parameter design method to retrieve data from the database into AutoCAD, which can read data routinely from the database, output the designed data into the computer-aided system and then draft the parts systematically. This is shown in Figure 8 and 9.

This legacy system, proposed by Chang et al.

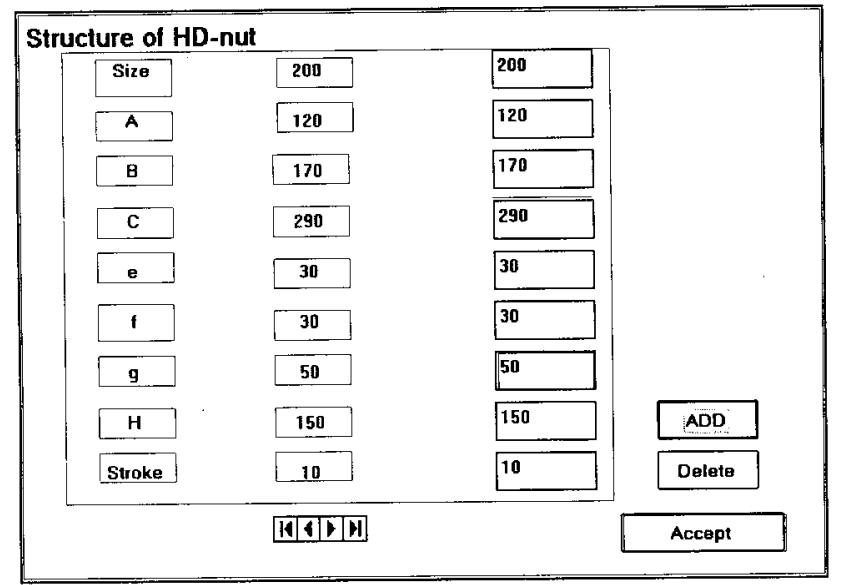

Fig. 5. Parts component repository data input.

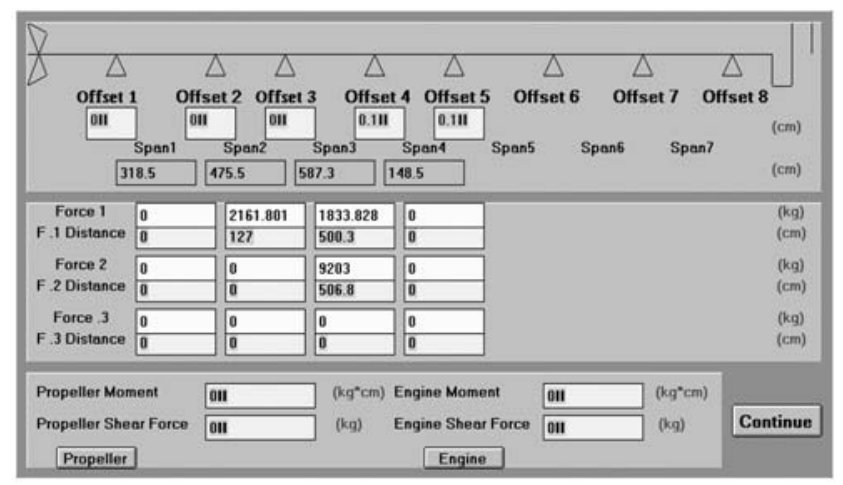

Fig. 6. Intelligent auxiliary operation.

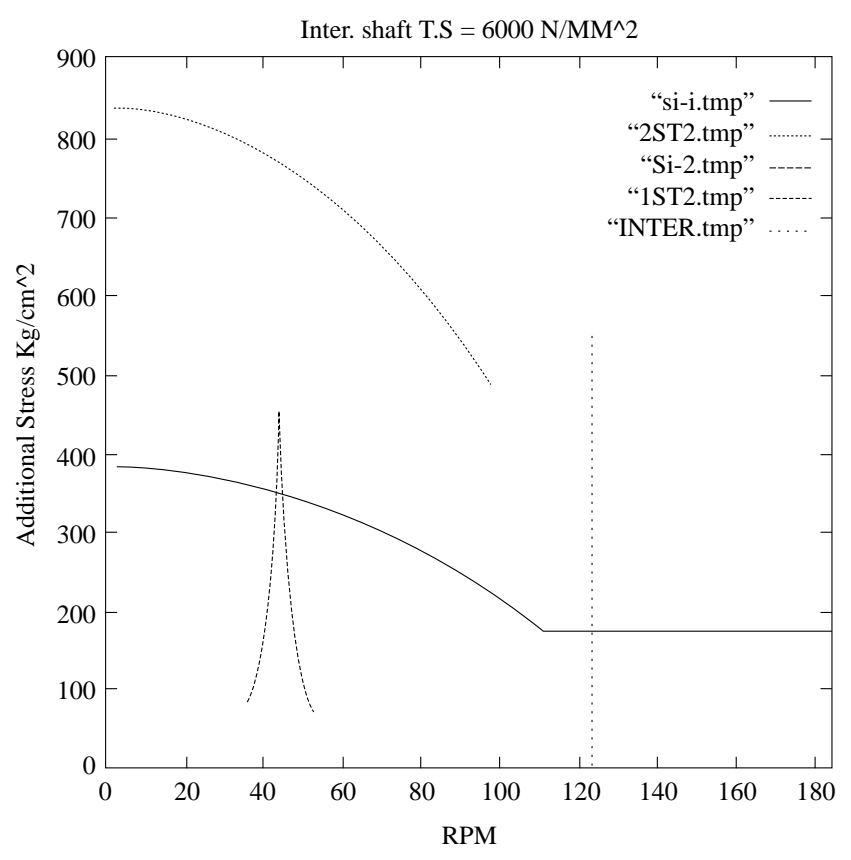

Fig. 7. Draft drawing output.

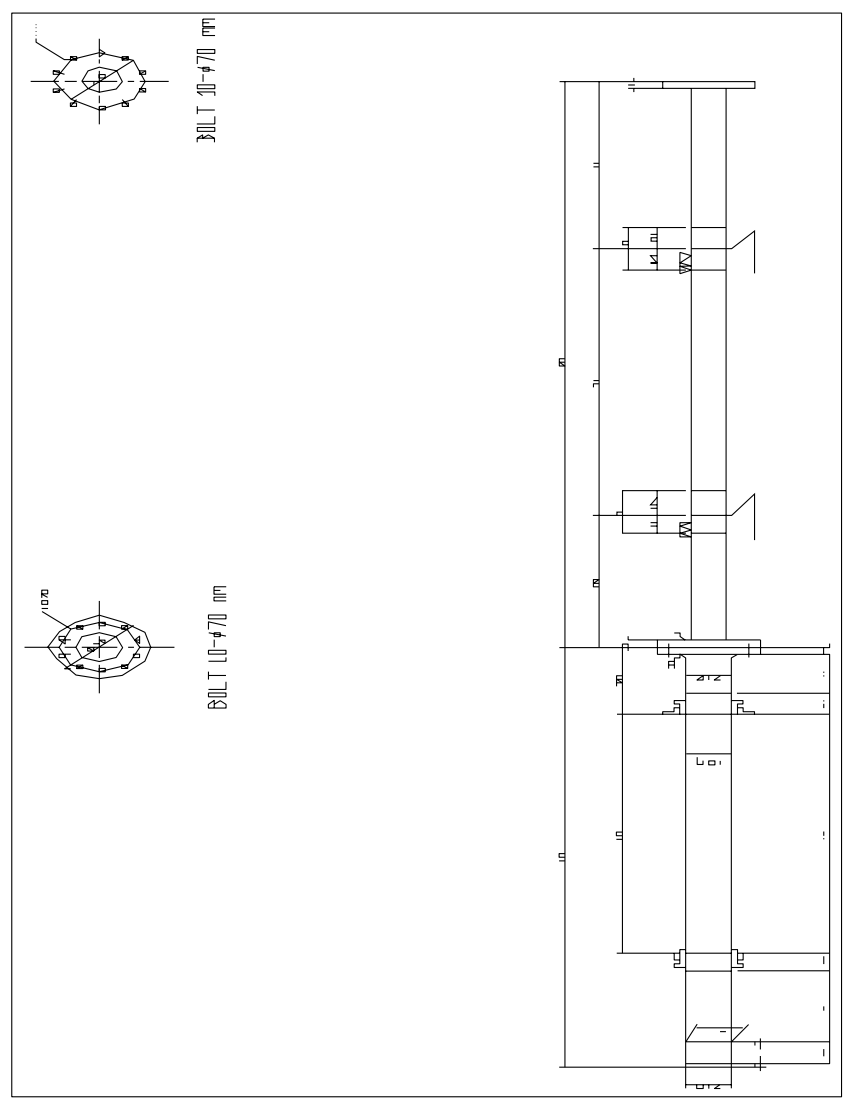

Fig. 8. CAD drawing for parametric design. 


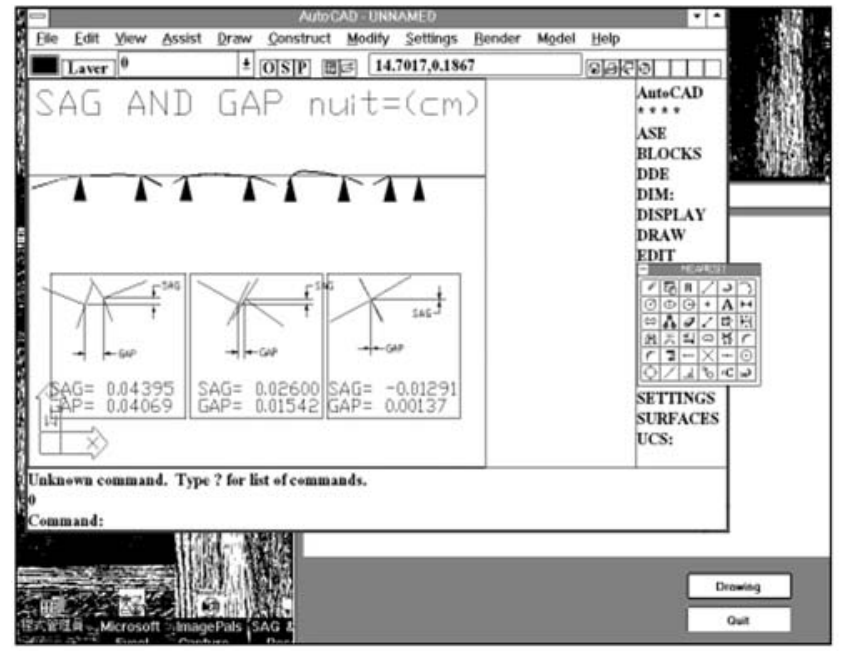

Fig. 9. CAD drawing output.

[10], was developed under a Microsoft Windows operating system, and designed with Fortran 77, Visual Basic, AutoLISP, Access and PowerBuilder. It also combines some useful database systems with computeraided drawing software such as SQL Anywhere Server, AutoCAD R12 for windows and Gnuplot. This system was fully tested. Compared with the results from the traditional methods of China Shipbuilding Corporation (the shaft design data of No. 579 - 260,000 DWT Oil Tanker and No. 383 -149,000 DWMT Bulk Carrier) [10], a satisfactory speed can be obtained for this design system. Having been combined with the introduction of the OODB and CORBA concepts, proposed in this paper, the data exchange efficiency is highly improved in every single division during data integration and data design. The new system proposed, using Windows NT 4.0 as the operating platform, adopts Borland $\mathrm{C}++$ Builder 4.0 language and its underlying ORB connection is IONA's Orbix 2.0 and ObjectStore PSE Pro for $\mathrm{C}++$ implemented as OODB.

\section{CONCLUSIONS}

This research utilizes a traditional computer-aided design system with the OODB database concepts to automate shaft design work. This system has four advantages. One is that the system will promote productivity and reduce cost. Second, the drawing output is standardized by the integrated computer-aided system that utilizes the parametric design, and its output can be referred to different designers. Third, a sharing and distributed component-oriented database approach is provided to facilitate data exchanging processes among different design departments. Lastly, the OODB object persistence and transaction management are efficiently coordinated and the concurrent data access is significantly increased. To solve problems regarding object exchanges among various design systems, an open CORBA standard interface is adopted to facilitate data exchanges among different design systems. In addition, design systems developed at different times, old systems or future development of auxiliary systems, are capable of making data exchanges convenient and efficient as long as the open COBRA standard is maintained and supported. As a whole, this integrated shaft design with the OODB system will increase the productivity of designs and promote the capability of the shipbuilding industry.

\section{REFERENCE}

1. Wu, J. K., Liu, T. H., and Fischer, G. W., "PDS/STEPBased Information Model for CAE and CAM Integration," International Journal of Systems Automation: Research and Applications (SARA), Vol. 2, pp. 375-394 (1992).

2. Boothroyd, G., "Product Design for Manufacture and Assembly," Computer Aided Design, Vol. 26, No. 7, pp. 505-520 (1994).

3. Seto, F., Uesugi, N., et al., "Application of CIM for Shipbuilding," International Conference on Computer Applications in Shipbuilding, Vol. 1, pp. 115-130 (1997).

4. Ross, J. M., and Horvath, J. A., "Shipbuilding CAD/ CAM/CIM: How World-Class Companies Are Applying the State of the Art," International Conference on Computer Applications in Shipbuilding, Vol. 1, pp. 3752 (1997).

5. Staal, A., and Tepper, G., "The Effect of CAD/CAM/ CIM in Shipbuilding as It Becomes a Part of the Infrastructure Between Subcontractor and Yards," International Conference on Computer Applications in Shipbuilding, Vol. 2, pp. 425-438 (1997).

6. Catell, R. G. G., Barry, D. K., and et al., Object Database Standard: $O D M G$ 2.0, Morgan Kaufman Publishers (1997).

7. Object Management Group, The Common Object Request Broker: Architecture and Specification, Revision 2.2, Object Management Group Inc., Framingham, MA (1998).

8. Amirbekyan, V., and Zielinski, K., "The Role of Transaction Management in CORBA/ODB Integrated Systems' Performance," Proc. ACM SIGSAC, pp. 733740 (2000).

9. Sheu, R. K., Liang, K. C., et al., "A New Architecture for Integration of CORBA and OODB," IEEE Trans. Knowledge and Data Engineering, Vol. 11, No. 5, pp. 748-768 (1999).

10. Chang, K. Y., and Wu, J. S., "Computer-Aided In- 
tegration System and Database in Application of Shaft Design," 9th Conf. On Naval Architects and Marine Eng., Taipei, Taiwan, pp. 201-206 (1996). (in Chinese)

11. Rules for Building and Classing, Steel Vessels American Bureau of Shipping (1976).

12. Piotrowski, J., Shaft alignment handbook, New York, 2nd Ed. (1995).

13. Shou, Y., Dong, J., and He, Z., "Integrate CAD to CAPP/ CAM with Object Oriented Engineering Database Using STEP,' IEEE TENCON '93, Beijing, pp. 592-595 (1993).

14. AutoLISP Release 12 Programmer's Reference, Autodesk (1995).

15. ADS Release 12 Programmer's Reference, Autodesk (1995).

\section{軸系設計自動化的電腦輔助系統與 零件元件庫之整合研究}

\author{
張 啓 隱
}

國立台灣海洋大學商船學系

詹景裕范啓明

國立台灣海洋大學資訊科學系

$$
\text { 摘 要 }
$$

本研究運用電腦整合設計的概念, 將傳統之船 用軸系設計予以自動化，利用參數式設計、交談式介 面、物件導向式資料庫及分散式處理架構爲設計基 礎, 將設計過程的強度計算、校中計算、扭轉振動計 算及下垂量與間隙計算運用電腦加以整合，不論投標 估價或完整設計, 皆可迅速完成設計及出圖, 不僅能 預估所需成本, 準確投標, 亦可輔助整體設計, 做到 節省人力、縮短工時及降低成本, 達到高效能之生 產。

關鍵詞：零件庫共享、電腦輔助整合、軸系設計、參 數設計、物件導向式資料庫、分散式處理。 